\title{
THE EFFECT OF THE BEARING OF YOUNG UPON THE BODY-WEIGHT AND THE WEIGHT OF THE CENTRAL NERVOUS SYSTEM OF THE FEMALE WHITE RAT.
}

\author{
By John B. Watson. \\ (From the Neterological Laburatory of the University of Chicago.) \\ With Plate VI.
}

By observations in this laboratory the results of which are as yet unpublished', the normal increase in the body weight of the female white rat, uninfluenced by the bearing of young, has been determined. In this connection, a question arose as to the effect on the body growth, if the females were allowed to breed normally. The present paper reports the results of an investigation carried out in answer to this question. In addition to the above, there arose the further question, as to the effect of the bearing of young upon the weight of the central nervous system, and on the percentage of water contained in it.

So far as the writer knows, only three men have published observations bearing directly upon the subject in hand; viz., Edlefsen, Hensen and Minot.

EDLEFSEN recorded the changes in the weight of 7 female guinea pigs from birth to the end of their first pregnancy. Unfortunately he compared the weight of the females during pregnancy with the weight of the males of a corresponding age. He made two points clear: Ist, the actual growth of the female guine 1 pig is slower during the period of gestation than that of the males of the same age during the same time; 2nd, that while the true body weight of the mother immediately after parturition is less than that of the male of corresponding age,

\footnotetext{
'It is expected that the results of this investigation will be published at an early date.
} 
still if we consider the weight of the mated females just at the end of the period of gestation (before partuition), or better if we add the weight of the young, immediately after birth to that of the mother, we shall find that the weight of the breeding female is in the ratio of $1.164: 1$ to that of the male. The relationship after parturition (not adding the weight of the young to that of the mother) is $0.848: \mathrm{I}$.

Hensen in an Anhang to Edlefsen's work, made some observations upon a litter of 4 guinea pigs, 3 females and I male, in order to determine the relationships between the growth of unmated females and males and thus supplement the results of EdLefsen. To control his results he mated one of the females. The following table presents his conclusions:

\begin{tabular}{|c|c|c|c|c|c|}
\hline & $\begin{array}{l}\text { Mated } \\
\text { female }\end{array}$ & $\begin{array}{l}\text { Unmated } \\
\text { female }\end{array}$ & $\begin{array}{l}\text { Unmated } \\
\text { female }\end{array}$ & Male & Ratio \\
\hline $\begin{array}{l}\text { I day after birth } \\
5 \text { I days after mating the }\end{array}$ & $59 \mathrm{gr}$. & $63 \mathrm{gr}$. & $57 \mathrm{gr}$. & & I:1.03:0.96:1 \\
\hline $\begin{array}{l}\text { one female } \\
\text { II days (immediately } \\
\text { after parturition) }\end{array}$ & $211 \mathrm{gr}$. & $220 \mathrm{gr}$. & $207 \mathrm{gr}$. & $228 \mathrm{gr}$. & $1: 1.04: 0.98: 1.08$ \\
\hline
\end{tabular}

The weight of the mother just before parturition was 612 grammes. In this table we find some slight ground for inferring that the males grow at least as rapidly as the unmated females. On the other hand, the figures point to the fact that breeding females, reckoning in the weight of their young, actually build up more bodily material, than either the unmated females or males during a corresponding period of growth.

Hensen then tried to determine the total increase in weight of one mated female during the period of gestation, apart from the increase in weight of her young. He began his reckoning at the time pregnancy first became noticeable. This happened on the 28th dity after conception. The female weighed 335 gr. at this age. In the remaining 39 days of pregnancy $(28+$ 39 days $=$ period of gestation) she herself gained $100 \mathrm{gr}$. in weight and produced $146 \mathrm{gr}$. of bodily substances in young and adnexa, i.e. 1.46 times more than she herself gained.

Minot tabulated the average changes in the weights of 66 female guinea pigs, from the beginning of the period of gesta- 


\section{I6 Journal of Comparative Neurology and Psychology.}

tion to parturition, and then again for 35 days immediately after parturition. The usual length of the period of gestation is from 67 to 68 days.

The average weight of the 66 pregnant guinea pigs just before delivery was $830.2 \mathrm{gr}$. Their average weight 3 days after delivery was $588 \mathrm{gr}$. The average weight of unmated females at that age, he had previously determined from many observations to be $532.1 \mathrm{gr}$. Thus it appears that at the end of pregnancy, the breeding females were heavier than those not allowed to breed, by about $55.9 \mathrm{gr}$. Minot's tables presenting the average alterations of weight of these 66 guinea pigs from the 35 days immediately after the delivery of their young, show that there is a very great loss of weight, especially marked during the earlier days of this period. Subsequently there is a slower loss in weight continuing for about three weeks, after which recovery begins.

Owing to the destruction of Misor's pigs-the story of which has become classic in the annals of American researchfurther investigation of this subject was cut short.

If we compare the results of EdLEFsen and Hensen's observations on the growth of gestating guinea pigs during their first pregnancy, with those of MinoT, we find a contradiction. EdeEFsen and Hensen conclude that the growth of the gestating females, when considered apart from the young developing in them, is slower than that of either the unmated females or males. Minot, on the contrary, concludes that the mated females immediately after partuition are heavier than the corresponding unmated femaies by $55.9 \mathrm{gr}$. On account of the large number of animals with which MINOT worked, his results are probably the more reliable.

\section{Observations upon the Body-weight of the White Rat.}

The writer's observations were begun upon a series of rats in the spring of 1903 and were continued for approximately one year. The females under observation were selected from five litters of rats born in April and May of that year. The 
rats in these litters were of good stock, strong, healthy, and large for their age.

In the following description of results, these five groups are referred to under the letters $A, B, C, D$, and $E$. At the beginning of the experiments

\begin{tabular}{cccccc} 
Group & A & contained & 5 & female rats \\
" & B & " & 3 & " & " \\
" & C & " & 4 & " & " \\
" & E & " & 4 & " & " \\
\multicolumn{7}{c}{ Total } & $\frac{5}{2 I}$ & &
\end{tabular}

Each of the above-named groups, at 70 days of age (the age at which sexual maturity is reached), was divided into approximately equal sub-groups, one containing the rats which were to be mated, the other, those which were to remain unmated.

Since we desired to make the condition for growth as nearly ideal as possible, we fed the rats used in this experiment wery carefully, giving them always a rich and varied diet. Baker's bread, softened with unskimmed milk, was the chief article of food. Since food of this character is likely to sour if left in the cages, only so much of it was given as could be consumed by the rats from one period of feeding to the next. Sunflower seed and cracked corn were always kept in the cages. Vegetables and meat were given once a week. Great care was taken to avoid surfeiting the rats. They were fed each morning between nine and ten o'clock.

The rats were weighed once a week, and weighing came always before feeding.

The experiment was conducted in a warm, sunny room, the temperature of which was kept constantly above $70^{\circ}$ Fahrenheit.

At 70 days of age ${ }^{1}$ the rats destined to bear young were

\footnotetext{
${ }^{1}$ At this age the average weight of the unmated rats approximately equalled that of the mated. A slight difference, however, existed in favor of the mated rats ( $2 \mathrm{gr}$. heavier on the average).
} 


\section{8 Journal of Comparative Neurology and Psychology.}

mated with the largest males in the laboratory. (These males weighed about 400 grammes). The males were kept in the cages until the females showed signs of pregnancy, and were then removed. Twenty one days is the usual length of the period of gestation. In nearly every case large litters were born-in some cases the litters contained as many as 14 young. At the end of twenty days the young were removed from their mother. She was then allowed to recover completely. This took, usually, from 30 to 50 days. When recovery was complete, the males were again introduced, and the same routine followed, until each mated rat had born three litters. When recovery was complete from the birth of the third and final litter, the experiment, so far as the body-weight was concerned, was at an end.

The unmated rats, of course, kept to the even tenor of their way. The records previously referred to, show the normal rate of the body growth in the unmated females. In the present experiment we again recorded the weight of unmated females, in order to have a control series with which to compare the mated rats. By subjecting both the mated and the unmated rats to exactly the same conditions as regards food, temperature, etc., we hoped to be able to isolate the influence of breeding on the growth of the body, However, if one compares the growth-curve of the unmated rats in this paper with the records referred to above, it will be found that, notwithstanding the better quality of food used in the present case, no very great difference in the body growth in the two cases can be observed.

The following table presents for comparison the record of the weights, at the ages given, of the mated and unmated individuals of Group C. This table gives a good illustration of what occurred in the four other groups.

Plate VI shows separately in graphic form the changes in the body weight of each of the above mated and unmated rats of Group C.

A study of this table and plate shows the fluctuations in the body weight of the mated rats, due to pregnancy, suckling. 
of young, etc. The general features of the table are clear, but one point is worthy of note. Immediately after the birth of the young, the mated rats are much heavier than the unmated. ${ }^{2}$ The mated animals, during pregnancy, seem to have the power of storing up in some way (fat?) the products obtained from

\section{TABLE I.}

Showing the average body weight, at the ages given, of the two mated and the two unmated rats of Group $C$. $^{1}$

\begin{tabular}{|c|c|c|c|}
\hline & Unmated & Mated & \\
\hline At 70 days & I16. I & I 20.9 & Mated at this age. \\
\hline $8 \mathrm{t}$ & I 29.4 & $129 \cdot 1$ & Pregnant. \\
\hline 92 & 143.0 & 176.4 & " \\
\hline 100 & 148.1 & 163.5 & $\begin{array}{l}\text { Young born } 6 \text { and } 3 \text { days before } \\
\text { respectively. }\end{array}$ \\
\hline 107 & I 50.9 & I 70.6 & \\
\hline 114 & 153.7 & 162.6 & Young very large: removed. \\
\hline I 21 & 160.1 & & ) \\
\hline 128 & 162.5 & 174.6 & \\
\hline I35 & $16 z .8$ & 170.7 & Recovery. \\
\hline 142 & 163.5 & 171.6 & 1 \\
\hline I 49 & 163.1 & 169.0 & 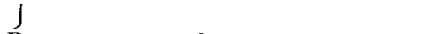 \\
\hline 156 & I68. I & 176.5 & Recovery complete. \\
\hline 163 & I68.5 & 184.0 & Mated one day before. \\
\hline 170 & $169 \cdot 3$ & 204.2 & Pregnant. \\
\hline 177 & $171 \cdot 3$ & 235.1 & " \\
\hline 184 & 174.1 & & \\
\hline I9I & 177.4 & 218.8 & $\begin{array}{l}\text { Young born } 12 \text { and } 5 \text { days before, } \\
\text { respectively. }\end{array}$ \\
\hline 198 & 177.6 & 227.6 & \\
\hline 205 & 180.3 & 225.7 & Young removed. \\
\hline 212 & 187.2 & 226.3 & One rat ill. \\
\hline 219 & IgO.I & 226.0 & a 4 a 6 \\
\hline 233 & 190.8 & $222.5^{1}$ & The sick rat had to be killed. \\
\hline 240 & I91.7 & $235 \cdot 7$ & $\begin{array}{l}\text { The average rose after killing } \\
\text { the other rat. }\end{array}$ \\
\hline 247 & $193 \cdot 3$ & 220.2 & Slightly ill. \\
\hline 254 & I 94.0 & 2260 & Mated for third and last time. \\
\hline $26 \mathrm{i}$ & 198.6 & 235.8 & Pregnant. \\
\hline 275 & I98.I & & \\
\hline 282 & 192.4 & 239.0 & $\begin{array}{l}\text { A litter of } 14 \text { young was born } \\
6 \text { days before. }\end{array}$ \\
\hline 296 & 19o.I & & Exhausted : young removed. \\
\hline $3 \mathbf{I} 7$ & 185.1 & 217.0 & $\begin{array}{l}\text { Rapid recovery after removal } \\
\text { of young. }\end{array}$ \\
\hline 345 & 197.1 & 219.4 & Final average. \\
\hline
\end{tabular}

'The above average for the mated rats is based upon the record of two individuals until the $233^{\text {rd }}$ day; thereafter, upon one.

${ }^{2}$ Minot: $o p$. cit. There is one difference between the guinea pig and the rat as regards the loss of weight during lactation. The loss in the guinea pig is most rapid during the first three or four days after parturition. Just the 


\section{Journal of Comparative Neurology and Psychology.}

their food. ${ }^{1}$ If one takes into account the great strain of suckling ten or twelve young for the period of twenty days, one can easily understand that some such provision as this is necessary. This surplus in weight is largely lost during the time the mother is suckling her young.

\section{Observations upon the Nervous System of the White Rat.}

As soon as the observations on the body growth were completed, the rats were killed, and the separate weights of the brain and spinal cord, together with the percentage of water in each of these parts were determined. The cord was severed from the encephalon at the tip of the calamus scriptorius. The spinal roots were cut as close to the cord as possible.

After the weight of the fresh brain and cord was found, the percentage of water present in each was determined. The tresh brains and cords were put in an oven and subjected for eight days to a constant temperature of $90^{\circ}$ Fahrenheit. They were then taken from the oven and cooled for thirty minutes in a sulphuric acid drying-chamber. The weight of the dried brains and cords was found, and with this completion of the data, the percentage of the water present in each was determined.

Table II gives the final results for both the mated and the unmated series of rats, on the weight of the body, the weight of the encephaion and cord, and the percentage of water present in each.

reverse is true in the case of the rat. The older the young of the rat up to 25-30 days, the greater the demand upon the mother's milk supply and the consequent increasing exhaustion of the mother. If the litter is large, the weight of the mother is sometimes reduced to a weight which is below that of the corresponding unmated rats. The explanation is, of course, that the young guinea pigs are relatively large when born and become independent of the mother much earlier than the young rats.

'Minot. See reference above, p. 145. 
TABLE II.

I. Final Body Weights.

Mated :

Unmated: Average body weight. Average body weight.

Age when

killed.

$\begin{array}{ccccc}\text { Group A } & \text { (2 rats) } 196.2 \mathrm{gr} . & \text { (2 rats) } 206.9 \mathrm{gr} . & \text { 380 days. } \\ \text { “ B } & \text { (I rat) } 232.0 \mathrm{gr} . & \text { (2 rats) } 197.0 \mathrm{gr} . & 36 \mathrm{r} \text { days. } \\ \text { “ } & \text { C } & \text { (1 rat) } 219.4 \mathrm{gr} . & \text { (2 rats) } 197.1 \mathrm{gr} . & 345 \text { days. } \\ \text { “ D } & \text { (2 rats) } 237.0 \mathrm{gr} . & \text { (I rat) } 203.0 \mathrm{~g} . . & 320 \text { days. } \\ \text { “ E } & \text { (2 rats) } 246.0 \mathrm{gr} . & \text { (3 rats) } 234.8 \mathrm{gr} . & 309 \text { days. } \\ \text { Average } & \text { (8 rats) } 226.2 \mathrm{gr} . & \text { (10 rats) } 210.9 \mathrm{gr} . & \end{array}$

2. Brain Weight.

Mated :

Average brain weight.

Group A (2 rats) $1.8152 \mathrm{gr}$.

“ B (I rat) $1.774^{\circ} \mathrm{gr}$.

“ C (1 rat) $1.8108 \mathrm{gr}$.

“ D (2 rats) $1.8443 \mathrm{gr}$.

“ E (2 rats) $1.9820 \mathrm{gr}$.

Average (8 rats) $1.8585 \mathrm{gr}$.
Unmated :

Average brain weight.

(2 rats) $1.7461 \mathrm{gr}$.

(2 rats) $1.7974 \mathrm{gr}$.

(2 rats) $1.7972 \mathrm{gr}$.

(1 rat) 8.8 .26 gr.

(3 rats) $1.9576 \mathrm{gr}$.

(Io rats) $1.8397 \mathrm{gr}$.

3. Spinal Cord Weight.

Mated:

Average cord weight,

Group A (2 rats) $\quad .6244 \mathrm{gr}$.

“ B (I rat) $.6047 \mathrm{gr}$.

“ C (I rat) $.5945 \mathrm{gr}$.

“ D (2 rats) .6400 gr.

“E (2 rats) .66r9 gr.

Average (8 rats) $\quad .6317 \mathrm{gr}$.
Unmated:

Average cord weight.

(2 rats) $.5812 \mathrm{gr}$.

(2 rats) $.5983 \mathrm{gr}$.

(2 rats) $.5797 \mathrm{gr}$.

(I rat) $.5989 \mathrm{gr}$.

(3 rats) $.6364 \mathrm{gr}$.

(10 rats) .6025 gr.

4. Percentage of Water in Brain.

Mated:

Average percentage af Water.

Group A (2 rats) $77.24 \mathrm{gr}$.

“ B (r rat) $77.47 \mathrm{gr}$.

“ C (I rat) $77.72 \mathrm{gr}$.

“ D (2 rats) $77.50 \mathrm{gr}$.

“E (2 rats) $77.56 \mathrm{gr}$.

Average (8 rats) $77.47 \mathrm{gr}$.
Unmated :

Average percentage of Water.

(2 rats) $77.20 \mathrm{gr}$.

(2 rats) $77.28 \mathrm{gr}$.

(2 rats) $77.70 \mathrm{gr}$.

(1 rat) $77.40 \mathrm{gr}$.

(3 rats) $77.32 \mathrm{gr}$.

(10 rats) $77.37 \mathrm{gr}$.

The two mated females in Group A were not as healthy as the other rats used in this experiment. After giving birth to their young, sores nearly always appeared on their necks. These grew steadily worse until the young were removed. After removal of the young, the sores would heal over completely, only to reappear at the next periad of lactation. 
522 Journal of Comparative Neurology and Psychology.

TABLE II-(Continued).

5. Percentage of Water in Cord.

Mated:

Average percentage of Water.

Group A (2 rats) $68.6 \mathrm{I} \mathrm{gr.}$

“ B (c rat) 68.37 gr.

" C (i rat) $68.52 \mathrm{gr}$.

“ D (2 rats) $6 \$ .16 \mathrm{gr}$.

" E (2 rats) 68.8 I gr.

Average (8 rats) $68.5^{\mathrm{I}} \mathrm{gr}$.
Unmated: Average percentage of Water.

(2 rats) $68.44 \mathrm{gr}$.

(2 rats) $68.05 \mathrm{gr}$.

(2 rats) $68.69 \mathrm{gr}$.

(I rat) $67.88 \mathrm{gr}$.

(3 rats) $68.23 \mathrm{gr}$.

(10 rats) 68.29 gr.

\section{Conclusions.}

I. The groups of mated rats grew to be somewhat heavier than the unmated groups. This was found to be true in four out of the five groups, Group A being the exception (see note, p. $52 \mathrm{r}$ ). The mated individuals were, on the average, 9 $\%$ heavier than the unmated.

2. The mated rats had both absolutely and proportionately the heavier central nervous systems.

3. The weight of the brain, in the mated rats, was however not so heavy as we should have expected from the body weight. Assuming that the brain weight should increase among mature rats in proportion to the $V^{4}$ - of the body weight ${ }^{1}$ and taking the unmated rats as the standard, we find that the brain weight observed in the mated rats would correspond to a body weight of $219.5 \mathrm{gr}$. But the observed body weight is 226.2 gr. We draw the conclusion that the mated animals were somewhat fatter than the unmated-a conclusion which harmonizes with the facts observed at autopsy.

4. The spinal cord was disproportionately heavy in the mated groups. From the laboratory records of breeding females of about the same weight, it appears that one gram of increase of body weight is accompanied by .0020 gr. of increase in the weight of the cord. If we take the relation between the

'DuBors found that in man at maturity the brain weights were related as the $V^{4}$ of the body weights. DHéré and LAPrcque, have determined a like relation in dogs of different sizes. 
increase in the body weight of Groups $B$ and $C$ as compared with $\mathrm{D}$ and $\mathrm{E}$ (A being omitted: see note p. 521 ) of both the mated and unmated series, we find that in this case the increase of one gram of body weight is accompanied in the mated series by $.0032 \mathrm{gr}$. and in the unmated series by .001 2 gr. increase in the weight of the cord or on the average by .0022-nearly the value found from the laboratory records. If, then, we consider that the removal of the excessive fat on the mated series would reduce its body weight to $219.5 \mathrm{gr}$. when the animals were in the same condition as the unmated series, then the difference in body weights between the two series amounts to 8.7 gr. which would call for .OIgI gr. additional cord weight in the heavier animals. The observed difference in the two series is $.6317-.6025 \mathrm{gr}$., or $.0292 \mathrm{gr}$, which serves to show that the spinal cord of the mated rats is heavier than we should expect from their true body weight. Whether this excess has resulted from changes affecting the entire cord or only the lumbar regions, was not determined.

5. The brain and spinal cord of the mated individuals contained a slightly higher percentage of water. Only a single exception to this relation was found in the entire series of ten groups, namely in the case of the spinal cord in Group C.

6. In general the older groups had smaller brain weights than the younger. The diminution in brain weight according to age is nearly proportional in the mated and unmated groups. This change probably marks the beginning of senescence.

\section{Résumé.}

The effect of the bearing of young is to render the mated rats slightly heavier than the unmated-some of the excessive weight being due to the larger amount of fat present in the mated animals. The proportional brain weight is not appreciably affected, but the spinal cord is distinctly heavier in the mated series, thus making the central nervous system as a whole heavier. The percentage of water in both the brain and spinal cord is in nine cases out of ten greater in the mated groups. This is perhaps the most important difference estab- 


\section{Journal of Comparative Neurology and Psychology.}

lished by the foregoing investigation, but the interpretation must await a further study of the diminution of the percentage of water in the central nervous system with advancing age and the conditions which probably modify it.

\section{Blbliography.}

Dhéré and Lapicque. '98. Sur le rapport entre la grandeur du corps et le developpement de l'encéphale. Archives de Physiologie, No. 4.

DuBois, '98. Ueber die Abhängigkeit des Hirngewichtes von der Köpergrösse beim Menchen. Archiz f. Anthropologie, 25.

Edlefaen, '68. Ueber den Einflus der Schwangerschaft auf das Wachstum und des Wachstums auf Zahle und Gewicht der Jungen nach Beobachtungen am Meerschweinchen. Arbeiten aus dem Kieler Physiologischen Institut.

Gassner, '52. Ueber die Veränderung des Körpergewichtes bei Schwangeren, Gebärenden und Wochnerinnen. Monatsschrift $f$. Geburtskunde u. Frauenkrankheiten, 19.

Hensen, '68. Anhang zur Arbeit von Dr. Edlefsen. 1bid.

MInot, '91. Senescence and Rejuvenation. Jr. Physiology, 1, No. 2. 


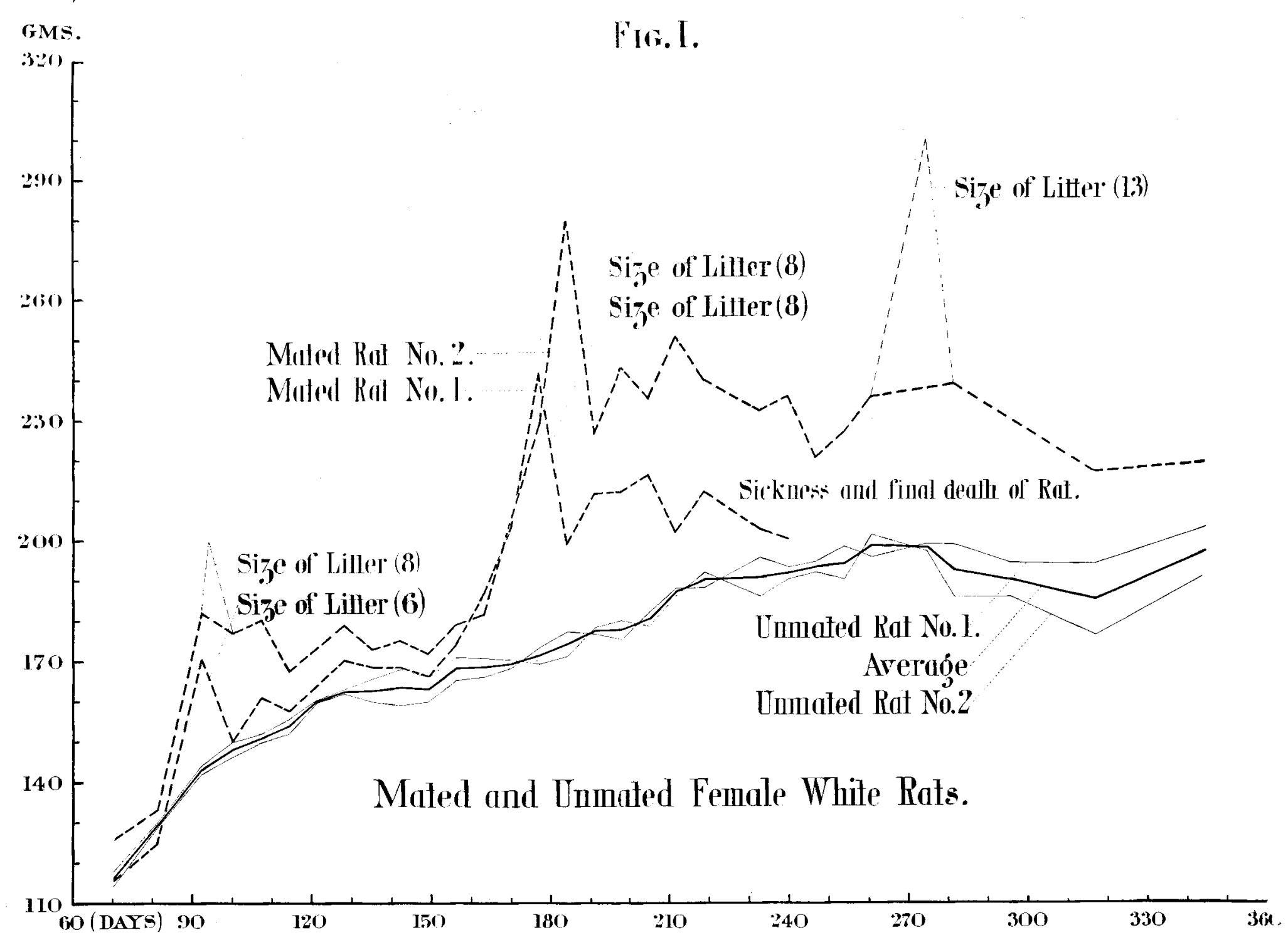

